\title{
Reduction of greenhouse gas emissions from renewable energy technologies in agricultural sectors of Uzbekistan
}

\author{
Anvar Anarbaev ${ }^{1}$, Obid Tursunov ${ }^{1, *}$, Dilshod Kodirov $^{1}$, Shavkat Muzafarov ${ }^{1}$, Aziz \\ Babayev $^{1}$, Amangul Sanbetova ${ }^{1}$, Lolita Batirova ${ }^{1}$, and Bakhadir Mirzaev ${ }^{1}$ \\ ${ }^{1}$ Tashkent Institute of Irrigation and Agricultural Mechanization Engineers, 100000, 39 Kari Niyazov, \\ Tashkent, Uzbekistan
}

\begin{abstract}
This paper presents the results of calculations to reduce greenhouse gas emissions in agricultural sectors of the Republic of Uzbekistan within the framework of the project: "Sustainable Agriculture Development and Climate Change Mitigation". The initial data were the characteristics of the implemented installations based on renewable energy sources for the period of 2014-2018. Most of these installations were biogas settings based on the principle of anaerobic fermentation, as well as solar water heating and photovoltaic stations. The calculations were performed according to the "AMS-III.D" and "AMS-I.J" methods by the "Global Environmental Fund" experts. The developed computer programs were applied to calculate the arrival of radiation and the duration of sunshine during the year on the territory of Uzbekistan. According to the calculations, the reduction of greenhouse gas emissions was 1338840.5 tons of $\mathrm{CO}_{2}$ for the indicated period during the operation of installations based on renewable energy sources. Within the framework of this project, the total potential of generating electric energy from biogas settings and solar photovoltaic stations at the amount of 10,424 MWh was estimated.
\end{abstract}

\section{Introduction}

In Uzbekistan, where about $45 \%$ of the population is engaged in agriculture, an obvious obstacle to the large-scale introduction of biogas technologies and renewable energy sources is the lack of necessary financial resources. Most of the villagers will not be able to afford the investments necessary for the introduction of a biogas installation, despite the quick payback and economic benefits received from the biogas installation. Attempts to reduce the cost of constructing a biogas installation should be undertaken in parallel with the development of credit and other financial systems that facilitate access to funds for the implementation of biogas installations.

In 2014-2018 In the Republic of Uzbekistan, the Agency for Restructuring of Agricultural Enterprises implemented the project "Support for agricultural enterprises. Phase II "with the participation of the International Development Association and the

*Corresponding author: obidtursunov@gmail.com 
Global Environment Facility grant project" Development of sustainable agriculture and mitigation of climate change". The purpose is to promote the dissemination of knowledge and the introduction of renewable energy technologies through the creation of pilot plots in farms to demonstrate the operation of biogas installations, energy-efficient irrigation pumps, solar water heating systems and systems for raising water from wells using a solar photovoltaic station.

A demonstration of renewable energy technologies included:

1. 23 pilot sites, with a demonstration of biogas installations (with volumes of bioreactors $6 m^{3}-20$ units, $60 m^{3}-1$ unit, $100 m^{3}-1$ unit and $600 m^{3}-1$ unit);

2. 5 pilot sites, with a demonstration of the technology of solar water heating systems (collectors);

3. 4 pilot sites, demonstrating the technology of a water-lifting system using a solar photovoltaic station.

The authors performed the calculation during the operation in 2015-2018 of these installations. The macroeconomic assessment of the profitability of introducing biogas installations took into account the positive effects on the energy sector, an increase in agricultural production, a decrease in health and environmental costs, an increase in employment and the replacement of imported gas and fertilizers with their own. Biogas technologies and renewable energy sources allowed us not only to support the state economy and environmental quality, but also provided opportunities for the people in remote sites to improve living conditions and welfare.

When processing raw materials, open storage of manure is also excluded. In addition, during processing, pathogenic microflora is partially destroyed. Thus, biogas technologies increase the life expectancy of the population and reduce the cost of drugs and treatment of intestinal diseases.

\subsection{Overview of sources}

By 2020, global methane emissions are estimated at 9,390 million metric tons of carbon dioxide equivalent (million tons of $\mathrm{CO}_{2} \mathrm{E}$ ). About 54 percent of these emissions come from five source industries.

Cost-effective technologies and methods to minimize the environmental impact of methane emissions from large agricultural sources are widely available and are used around the world. In addition to minimizing the impact on climate change, reducing methane emissions creates an alternative energy source, positively affects health and safety, and also has local benefits for the surrounding ecosystem. Many technologies and methods for reducing methane emissions simultaneously reduce emissions of volatile organic substances, hazardous air pollutants and other local air pollutants. This has a positive effect on the health of the local population and labor force. Since methane is an important precursor to tropospheric ozone, a decrease in methane also reduces the effects of ozonerelated factors on human health.

By 2020, global methane emissions are estimated at 9,390 million metric tons of carbon dioxide equivalent (million tons of $\mathrm{CO}_{2} \mathrm{E}$ ). About 54 percent of these emissions come from the five source industries that are the target of the Global Methane Initiative (GMI): agriculture (manure management), coal mines, municipal solid waste, household wastewater, and oil and gas systems. 


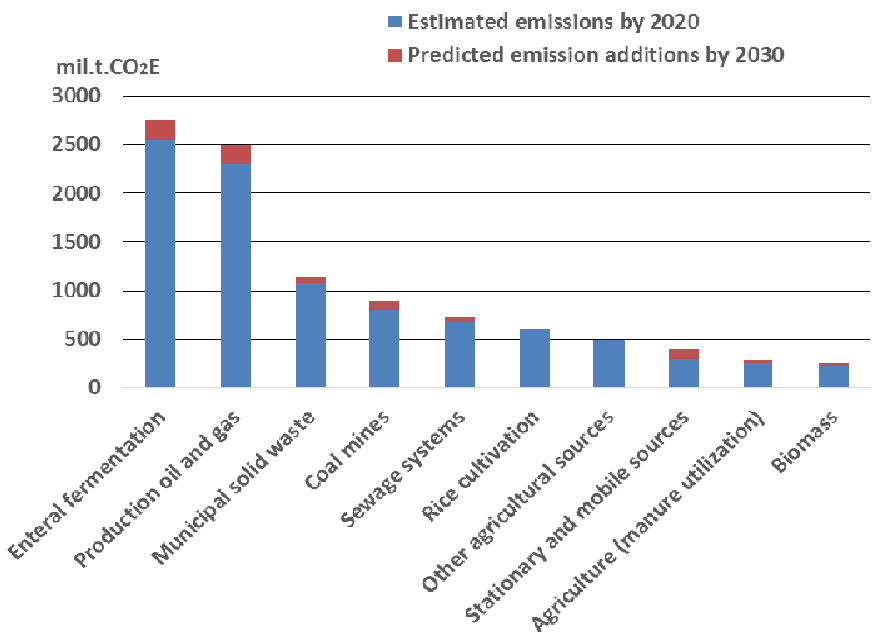

Fig. 1. Estimated and projected global anthropogenic methane emissions by sources by 2020, 2030

The increase in global anthropogenic methane emissions is projected to be almost 9 percent higher than expected levels in 2020, with 10,220 million metric tons of carbon dioxide equivalent (million tons of $\mathrm{CO}_{2} \mathrm{E}$ ) reaching 2030.

In the period from 2020 to 2030. the relative share in the formation of emissions for agricultural sectors (manure utilization), coal mines and domestic wastewater is projected to remain constant, while for the share of emissions from municipal solid waste and oil and gas industries an increase of about one percent of the estimated global methane emissions from anthropogenic sources (Fig. 2)

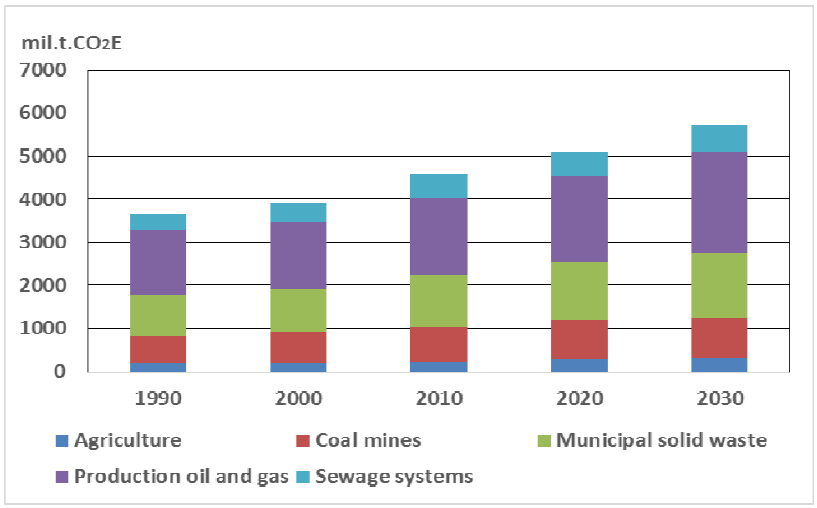

Fig. 2. World anthropogenic methane emissions, 1990-2030

For each of the following sectors - in agriculture, solid waste landfills and wastewater treatment systems, methane emissions are expected to increase by 5, 6 and 8 percent, respectively. Agriculture (manure management) has growing potential to reduce from 3 to 10 percent, depending on the increase in costs of the event from 15 to 30 US dollars per megaton of $\mathrm{CO}_{2} \mathrm{E}$. Raising costs to $\$ 60$ will create an additional 5 percent reduction, but with a longer payback period. Global emission reduction potential (GAP) at any cost is only 28 percent of its original value.

Anaerobic processing of livestock waste results in a reduction in greenhouse gas emissions that affect the climate. The use of biogas reduces carbon dioxide emissions by reducing the consumption of fossil fuels such as gasoline, coal, firewood. At the same time, 
due to the collection and use of biogas through the processing of manure, there is a decrease in emissions of the most important greenhouse gas - methane a. An increase in the presence of greenhouse gases in the atmosphere, which mainly include carbon dioxide, methane and nitrous oxide (laughing gas), leads to an increase in the temperature of the earth and climate change. Biogas installations reduce firewood consumption and reduce deforestation, reduce land degradation and the resulting natural disasters, such as flooding or desertification. Using $1 \mathrm{~m} 3$ of biogas instead of $1.3 \mathrm{~kg}$ of firewood reduces carbon dioxide emissions by $2.6 \mathrm{~kg}$, reducing carbon dioxide emissions by replacing the use of gasoline is about $1.6 \mathrm{~kg}$ per $1 \mathrm{~m}^{3}$ [1]. The natural formation of biogas is an important part of the biochemical carbon cycle of the planet. About 590-880 million tons of methane is released into the atmosphere each year through the action of microbes. About $90 \%$ of methane emissions occur through the decomposition of biomass, and the rest due to the occurrence of natural processes [1]. Until today, measures to reduce global warming have mainly related to the reduction of carbon dioxide emissions due to its high concentration in the atmosphere, but other gases have a much stronger greenhouse effect.

Methane makes up only $20 \%$ of the greenhouse gas content in the atmosphere, but its potential impact on the climate is 21 times higher than that of carbon dioxide. Therefore, reducing methane emissions is more effective at preventing climate change than reducing carbon dioxide emissions. The reduction in methane emissions from the processing of one ton of manure is about 90 kilograms of carbon dioxide equivalent [2]. Agricultural methane emissions account for about 33\% of global methane emissions from human activities. Livestock production is responsible for $16 \%$, rice cultivation for $12 \%$ and livestock waste for 5\% [3]. While 16\% of global methane emissions from ruminant digestion (about 80 million tons per year) are unlikely to be reduced, methane emissions from livestock waste can be collected and used through anaerobic processing in biogas installations. The exact amount of methane emissions depends on the type of animal, its feed and manure storage systems: in developed countries, emissions from dairy animals are $0.32 \mathrm{~m} 3$ of methane per kilogram of dry manure, and in developing countries only $0.25 \mathrm{~m} 3$ [4].

Through anaerobic processing of livestock waste and the use of methane for energy production, a global reduction of 13.24 million tons of methane per year can be achieved. In total, this represents about $4 \%$ of global anthropogenic emissions of methane.

\section{Research Methods}

Successful large-scale implementation of biogas technologies and renewable energy sources requires taking into account the mutual influence of the existing climatic, social, economic and environmental conditions, increasing public and political awareness, as well as state support. Biogas technologies are fundamentally applicable in most climatic zones, but the cost of their implementation increases with decreasing ambient temperature, since in such cases additional heating and insulation of the biogas installation are necessary. Biogas systems without heating and insulation do not show satisfactory results at average air temperatures below $15{ }^{\circ} \mathrm{C}$ [5]. A small amount of seasonal and annual precipitation leads to the expansion of cattle grazing instead of stall keeping. This reduces the amount of manure obtained, ready for processing in biogas installations [6].

Calculations to reduce greenhouse gas emissions were carried out for two points according to the baseline [7] and project scenarios according to the methods developed for grants of the Clean Development Mechanism:

a) the basic scenario, when manure is stored in heaps on the territory of farms and periodically, several times a year (mainly in autumn and spring), is exported to the fields to fertilize the soil. Usually, before the next removal to the field, on the farm's territory, the storage of manure creates conditions for anaerobic fermentation, in which methane $\left(\mathrm{CH}_{4}\right)$ is 
formed and released into the atmosphere. Worldwide, methane emissions from an inefficient waste management system make up about 1/4 of all greenhouse gas emissions. Emissions of methane converted to greenhouse gases were determined by the formula

$$
B E_{C H_{4} y}^{\text {base }}=G W P_{C_{4}} \times D_{C_{4}} \times U F_{b} \times \sum_{j, L T} M C F_{j} \times B_{0, L T} \times N_{L T} \times V S_{L T, y} \times M S \%_{B L, j}
$$

$\mathrm{GWP}_{\mathrm{CH}_{4}}$ - global warming potential for methane; $D_{\mathrm{CH}_{4}}$ - methane density $0.00067 \mathrm{t} / \mathrm{m} 3$ at a temperature of $20^{\circ} \mathrm{C}$ and a pressure of $1 \mathrm{~atm}$; $L T$ is the type of animal; $J$ is the index for the waste treatment system; $U F_{b}$ - correction factor taking into account model inaccuracies; $M C F_{j}$ - annual methane recalculation factor for the waste treatment system; for Uzbekistan it is recommended to use coefficients at an average annual temperature of $15^{\circ} \mathrm{C} ; B_{0, L T}$ - the potential maximum amount of methane that can be generated from a certain amount of volatile solids produced by animals of type $L T$ in the year $\mathrm{y} \mathrm{m}^{3} \mathrm{CH}_{4} / \mathrm{kg}$ dry matter; $N_{L T}$ - the average annual number of animals of type $L T$ in year $y ; V S_{L T, y}{ }^{-}$ annual amount of volatiles produced by one animal $L T, \mathrm{~kg}$ solids / head / year; $M S \%_{B L, j}{ }^{-}$ part of the total amount of manure entering the waste treatment system

When using a biogas installation, manure is processed. In this case, the reduction of volatile solids is evaluated in accordance with the parameters according to the formula [4]

$$
E R_{\mathrm{CH}_{4} \mathrm{y}}^{\text {base }}=\mathrm{BE}_{\mathrm{CH}_{4} y}^{\text {base }} \cdot\left(R V S_{2}-R V S_{1}\right)
$$

$R V S$ is the relative decrease in volatile solids of the previous stage of manure processing [7]. Compared to open manure storage, anaerobic digestion in biogas installations reduces emissions by

$$
R V S_{2}-R V S_{1}=70-30=40 \% .
$$

b) the project scenario, when the creation of a farm energy supply complex, consisting of a installation for the production of biogas from animal waste for heating and gas use in electricity-generating gas generators. Using this complex will allow the farm to switch to an autonomous energy supply system, save electricity, coal and wood fuel

Emission reduction is calculated on the basis of the generated thermal energy when burning a certain amount of biogas [7]:

$$
E R_{C H_{4} y}^{\text {project }}=G W P_{\mathrm{CH}_{4}} \times V_{\text {bioreactor }} \cdot \sum_{k=1}^{N} B S_{k, y} \times k_{C_{4}} \times \eta_{P J / B L} \times\left(365 \cdot \mathrm{NCV}_{\mathrm{CH}_{4}}\right)-P E_{P L, y}
$$

$B S_{k, y}$ - heat energy consumption due to biogas burning generated by unit $\mathrm{k}$ in year $\mathrm{y}$ (mass or volume, dry basis) was adopted in projects regarding the bioreactor volume $0.13 \mathrm{Nm}^{3}$ / $\left(\mathrm{m}^{3} \cdot\right.$ day $)$, it says about cubic meters per hour. normal temperature conditions from $20^{\circ} \mathrm{C}$; $V_{\text {bioreactor }}$ - bioreactor volume, $\mathrm{m}^{3} ; k_{\mathrm{CH}_{4}}$ - specific emission factor (tC/ TJ); $\eta_{P J / B L}-$ efficiency coefficient of a biogas installation compared to a traditional one; $N C V$ is the calorific value of biomass (GJ / mass unit or volume, dry residue), with a methane content of $60 \%$ in biogas; $P E_{P L, y}{ }^{-}$biogas leaks, emissions from physical biogas leaks $P E_{P L, y}$ accepted according to the methods [8] in $10 \%$ of the maximum amount of methane that this system can produce.

It was taken into account that the equipment of biogas installations with a capacity $6 \mathrm{~m}^{3}$ of biogas per day does not allow using it in winter due to bad thermal insulation.

The main purpose of the hot water obtained from solar water heating installations in farms is the sanitary-hygienic cleaning of cowsheds and pasteurization of 20 tons of milk per day. 
Calculation of the reduction of carbon dioxide $\left(\mathrm{CO}_{2}\right)$ emissions is based on the prevention of emissions during their use from the burning of fossil fuels, $t$ ons per year:

$$
\mathrm{BE}_{\mathrm{CO}_{2}}=\sum_{i=1}^{n}\left(B_{i} \cdot Q_{i}^{r} \cdot k_{\mathrm{Ci}_{i}} \cdot k_{\mathrm{CO}_{2}}\right)
$$

$\mathrm{BE}_{\mathrm{CO}_{2}}$ - annual $\mathrm{CO}_{2}$ emissions in weight units (tons / year); $B_{i}$ - actual fuel consumption for the year (thousand tons / year); $Q_{i}^{r}$ - calorific value, TJ / thousand t (MJ / kg); $k_{\mathrm{CO}_{2}}-$ specific carbon emission coefficient ( $\mathrm{tC} / \mathrm{TJ}$ ); $k_{\mathrm{Ci}}=3.67$ - coefficient (degree) of complete oxidation of carbon to the formation of carbon dioxide, $\mathrm{t} \mathrm{CO} 2 / \mathrm{tC} ; n$ is the number of types of fuel burned.

Emissions of other greenhouse gases $\mathrm{CH} 4$ and $\mathrm{N}_{2} \mathrm{O}$ also strongly depend on the technology of fuel combustion, which will be taken into account in calculations in biogas installations.

$$
B E=G W P \cdot \sum_{i=1}^{n}\left(B_{i} \cdot Q_{i}^{r} \cdot k\right)
$$

GWP - global warming potential for $\mathrm{CH}_{4},-21 ; \mathrm{NO}_{2},-310$.

Reducing $\mathrm{CO} 2$ emissions through the use of photovoltaic (PV) instead of installations generating energy by burning fossil fuels is determined through the amount of energy produced by the installation and the emission factor:

$$
B E_{y}=E G_{B L, y} \times E F_{y}\left(\mathrm{CO}_{2}\right),
$$

$B E_{y}$ - emissions per year ( $\left.\mathrm{t} \mathrm{CO}_{2}\right), E G_{B L, y}$ - the amount of electric energy received from the PV per year during the implementation of the Project CDM $(\mathrm{MW} \cdot \mathrm{h}), E F_{y}\left(\mathrm{CO}_{2}\right)-$ emission factor $\left(\mathrm{t} \mathrm{CO}_{2} / \mathrm{MW} \cdot \mathrm{h}\right)$.

The amount of electric energy received from PV per year depends on many factors, but first of all, on the power generated by PV, uneven solar radiation and the duration of sunshine during the year, especially for stations not using the sun tracking system. For the convenience of calculating the average power generated per year, the concept of the number of peak sundial is introduced. The term "peak sundial" means the average duration of the arrival of solar radiation during the day, which would irradiate a certain place if the Sun shone with intensity equal to the reference, i.e. at which certification of photovoltaic panels. Certification of photovoltaic panels, as a rule, is carried out at a density of the reference radiation flux equal to $1 \mathrm{~kW} / \mathrm{m}^{2}$. The value of the number of peak sundials throughout the year is constantly changing; therefore, for the convenience of calculations, its average value for the year $\left(n_{y}\right)$ is used. For the Republic of Uzbekistan, the average peak sunshine is 6 hours.

To calculate the amount of electric energy received from PV for the year, it used the following expression

$$
E G_{B L, y}=365 \times n_{y} \times P_{P V} / 1000,
$$

$E G_{B L, y}$ - amount of electric energy received from PV per year (MW $\left.\cdot \mathrm{h}\right) ;, n_{y}$ - average annual number of peak hours of sunshine (for the Republic of Uzbekistan $n_{y}=6$ hour), $P_{P V}$ - power generated by photovoltaic panels $\mathrm{PV}(\mathrm{kW})$.

\section{Results}

It is considered that the application of the methodology as an example of a demonstration site at the Inter Milk enterprise of the Syr Darya region with biogas equipment of $100 \mathrm{~m}^{3}$ and the presence of 250 dairy cows put into operation on 1.01.2018.

According to the baseline scenario, methane emissions are reduced to greenhouse gases for a given facility, ton $\mathrm{CO}_{2}$-eq.

$$
E R_{\mathrm{CH}_{4} y}^{\text {base }}=21 \times 0,00067 \times 0,94 \times 0,04 \times(20 \times 250) \times 250 \times(4,5 \times 250) \times 1 \times 0,4=68,56
$$


According to the project scenario, methane emissions reduction with conversion to greenhouse gases for this facility, ton $\mathrm{CO}_{2}$-eq.

$$
E R_{C H_{4} y}^{\text {project }}=21 \times 100 \cdot 47,45 \times 11 \times(0,5 \times 0,75) \times(365 \cdot 0,0359) \times(1-0,9)=13280,56
$$

Total in a year, the potential reduction in emissions will be in tons of $\mathrm{CO}_{2}$-eq.

$$
E R_{C H_{4} y}=68,56+13280,56=13349,12
$$

Given that the installation has worked up to now two months, at the moment this figure is in tons of $\mathrm{CO}_{2}$-eq.

$$
E R_{C H_{4} y}^{\text {H.B. }}=0,165 \times 13349,12=2202,605
$$

For the "Sohibkor" farm for a solar water heating system consisting of $46 \mathrm{~m}^{2}$ flat solar collectors, heat generation from solar energy per year will be 307.57 GJ according to the calculations. This carried out by the Chart program for the climatic conditions of the Tashkent region, is shown in Fig. 3.

Carbon dioxide greenhouse gas reduction

$$
B E_{\mathrm{CO}_{2}}=307 \times 25,15 \times 3,67 / 1000=28,39
$$

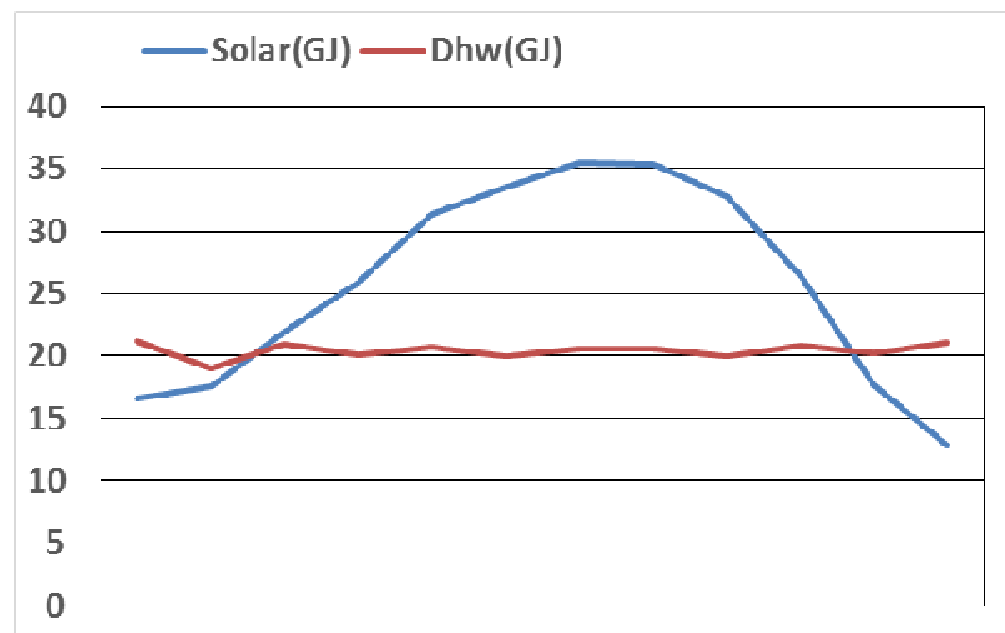

Jan Feb Mar Apr Mav Jun Jul Aug Seb Oct Nov Dec

Fig. 3. Calculation of the annual heat production of the installed solar water heating system for the farm "Sohibkor" of the Tashkent region

Methane $\mathrm{CH}_{4}$ reduction of greenhouse gas emissions

$$
B E_{\mathrm{CH}_{4}}=21 \times 307 \times 0,001 / 1000=0,006459
$$

Nitrogen dioxide $\mathrm{NO}_{2}$ greenhouse gas reduction

$$
B E_{N_{24}}=310 \times 307 \times 0,007 / 1000=0,667427
$$

Total reduction of greenhouse gas emissions, t. $\mathrm{CO}_{2}$-eq

$$
B E=28,39+0,006+0,667=29,06275
$$

Let consider that the application of the methodology as an example of one of the demonstration plots on water-lift systems using photovoltaic stations. We calculated the training site of the Tashkent region of the Tashkent Institute of Irrigation and Agricultural Mechanization Engineers.

The amount of electric energy received from the PV station for the year is determined using the expression (16):

$$
E G_{B L, y}=365 \times 6 \times 9,2 / 1000=20,1 \mathrm{MW} \cdot \mathrm{h} \text { per year }
$$


The emission factor in $\mathrm{tCO}_{2} / \mathrm{MWh}$ is determined. Since the power generated by the PV is $9.2 \mathrm{~kW}$, the emission factor for the water-lifting system will be

$$
E F_{y}\left(\mathrm{CO}_{2}\right)=1,4 \mathrm{t} \mathrm{CO}_{2} / \mathrm{MW} \cdot \mathrm{h}
$$

Determine the reduction of $\mathrm{CO}_{2}$ emissions due to the use of PV instead of the station generating energy by burning fossil fuels from expression (18):

$$
B E_{y}=20,1 \times 1,4=28,2 \mathrm{t} \mathrm{CO}_{2} \text { per year }
$$

Thus, the operation of the PV for the water-lifting system located at the training ground in the Tashkent region of the Tashkent Institute Engineers of Irrigation and Mechanization Agriculture will reduce the amount of $\mathrm{CO}_{2}$ emissions per year by 28.2 tons.

In total, for this project, taking into account the operating life of all the demonstration facilities during project loading, the installed biogas installations provide a reduction in greenhouse gas emissions of 1331566 tons of $\mathrm{CO}_{2}$-eq.

The installed Solar water heating systems provide a reduction in greenhouse gas emissions of 221,5 tons $\mathrm{CO}_{2}$-eq.

Total amount of $\mathrm{CO}_{2}$ emissions per year, which allows to reduce the demonstration plots implemented under the project with water-lift systems using photovoltaic stations, is 7052,5 tons of $\mathrm{CO}_{2}$-eq.

\section{Conclusions}

According to this study, the greatest effect on reducing greenhouse gas emissions from projects implemented in the republic when using renewable energy sources in agriculture is provided by biogas installations.

In total, according to the calculations, the reduction of greenhouse gas emissions was 1338840.5 tons of $\mathrm{CO}_{2}$ for the indicated period of 2014-2018 years during the operation of installations based on renewable energy sources in the republic. Total potential of generating electric energy from biogas installations and solar photovoltaic stations of this project in Uzbekistan in the amount of 10,424 MWh per year was estimated.

\section{References}

1. H.L. Foged, Energy from livestock manure, Position, technology and innovation in Denmark (2012)

2. S. Orsik, N.T. Sorokin, V.F. Fedorenko, Bioenergy: world experience and development outlook: scientific-analytica (2007)

3. G. Burg, R. Krista, V. Peter, Spec Renew Res Ag, 118 (2010).

4. J. Han, M. Mintz, M. Wang, Waste-to-Wheel analysis of Anaerobic-Digestion-Based Renewable Natural Gas Path-ways with the GREET Model (2011)

5. A. Wellinger, A. Lindberg, Biogas upgrading and utilization: Energy from Biological Conversion of Organic Waste (2006)

6. A.G. Fiapshev, Proceedings of an International Conference on Energy supply and energy saving in agriculture, 4, 281-284 (2014)

7. A.K. Kurmanov, J. VNIIMZH, 3, 170-177 (2014)

8. T. Simankina, I. Kibireva, A.Mottaeva, M. Gusarova, Adv. Intell. Syst. Comp. 983, 138145, (2019) https://doi.org/10.1007/978-3-030-19868-8_13 